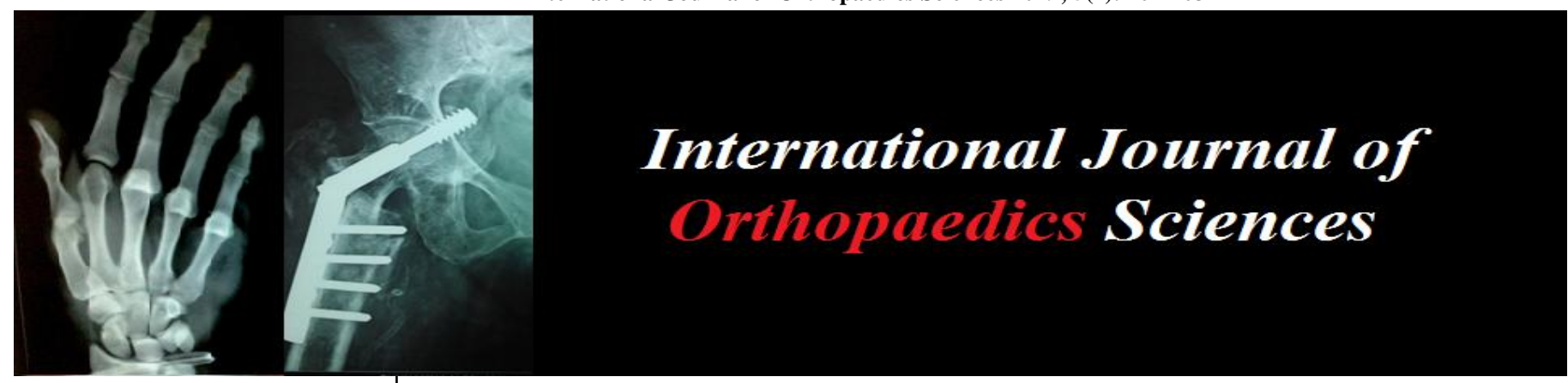

ISSN: $2395-1958$

IJOS 2019; 5(1): 401-403

(C) 2019 IJOS

www.orthopaper.com

Received: 15-01-2019

Accepted: 17-02-2019

Dr. Suganthi David D

Associate Professor, Department

of Orthopedics, Mount Zion

Medical College, Chayalode,

Adoor, Kerala, India

Dr. Anil Kumar SD

Associate Professor, Department

of Orthopedics, Mount Zion

Medical College, Chayalode,

Adoor, Kerala, India
Correspondence

Dr. Anil Kumar SD

Associate Professor, Department

of Orthopedics, Mount Zion

Medical College, Chayalode,

Adoor, Kerala, India

\section{Intra articular fractures of distal humerus in adults: Clinical profile}

\section{Dr. Suganthi David D and Dr. Anil Kumar SD}

DOI: https://doi.org/10.22271/ortho.2019.v5.i1g.70

\section{Abstract}

Non-articular medial epicondyle is closely related to ulnar nerve and is the point of attachment of ulnar collateral ligament. The articular surface of distal humerus makes an angle $4-8^{\circ}$ valgus with shaft axis. The articular segment projects anteriorly to the shaft at an angle of $40^{\circ}$. Medial epicondyle is in projected axis of shaft while lateral epicondyle is projected slightly forward from the axis. The study was conducted in Medical College, and there were 14 cases in the study in which 9 were males and 5 females. Age of the patients ranged between 25 years and 75 years with an mean age of 48.2 years. Among the 14 cases, 8 were caused by fall (57\%) and six were caused by Road Traffic accidents (43\%). Among the 8 patients operated before meantime of 6 day, 7 patients $(88 \%)$ had acceptable outcome (average score $86.4 \%$ ) and one had unacceptable outcome (score 70\%). Among the 6 patients operated after 6 days, 3 had acceptable outcome (average score 83.33\%) and 3 patients had non-acceptable outcome (average score $58.3 \%$ ).

Keywords: Intraarticular Fracture, Distal Humerus, Clinical Profile

\section{Introduction}

The elbow joint is a synovial joint of hinge variety it consists of articulation of capitulum and trochlea of distal humerus above and upper surface of head of radius and trochlear notch of ulna below.

Distal humerous widens distally in a coronal dimension, to a maximum between the medial and lateral epicondyles. From the lateral aspect bone narrows from proximal to distal in sagittal dimension before its distal most articular segment expands and juts anteriorly. Narrowest segment above the articular segment corresponds to widest portion in coronal plane. At their distal most point they are joined by the tie arch consisting of the articular segment the trochlea and capitulum. Capitulum is the distal most portion of lateral column, trochlea is intermediate between it and distal end of medial column, the medial epicondyle ${ }^{[1]}$.

Non-articular medial epicondyle is closely related to ulnar nerve and is the point of attachment of ulnar collateral ligament. The articular surface of distal humerus makes an angle $4-8^{\circ}$ valgus with shaft axis. The articular segment projects anteriorly to the shaft at an angle of $40^{\circ}$. Medial epicondyle is in projected axis of shaft while lateral epicondyle is projected slightly forward from the axis.

The recessed and thinned bone just cephalad to the waist of trochlea is the coronoid fossa and its centre part posteriorly is the olecranon fossa. These fossae are designed for the reception of radial head and the coronoid process and olecranon in full flexion and extension ${ }^{[2]}$

Safe screw placement assures no violation of these fossae. It is one of the most complicated and difficult fractures of distal Humerus to treat. It consists of vertical compression through articular surface commonly through trochlear sulcus into humeral fossae. From this area single transverse (or) two diverging oblique fractures through the supracondylar and humeral columns. Varying degree of separation is present from each other and the humeral fragments. It is a rare injury; unfortunately, very few surgeons have much experience in treatment. The average incidence is (3-4\%) per year-as per Massachusetts General Hospital) It occurs in middle- aged adults.

"Splitting of condyles "occurs due to wedge action of proximal ulnar articulating surface against trochlea. It can occur in flexion and extension. It can be produced by 
"minimal trauma" (e.g. fall in elbow) where the condyles are prestressed by the contraction of fore arm muscles in an attempt to break the fall. The forces applied to posterior aspect of flexed elbow $\mathrm{mm}$ be violent (e.g. Road traffic accidents).

There are two types of injury. One is "flexion type" where condyles are present anterior to the humeral shaft. In the "extension type"Ulna is directed anterior against the posterior aspect of trochlea separating the condyles and the same time supra condylar portion is fractured ${ }^{[3]}$.

Another mechanism was described by Wilson \& Cochrane, it occurs due to the splitting effect of humeral shaft as it is forced distally. In the extension type the humeral condyles lie behind the shaft. What ever the mechanism of injury there is always associated soft tissue injury, and some open lacerations extend into fracture site. There is usually loss of bony continuity, since the fragments are displaced by opposed muscle traction, as it pulls the epicondyles distally and rotates the condyles, so that articular surface face a more proximal direction. This converts the trochlear sulcus into a narrow inverted " $\mathbf{v}$ " and hence not congruous with the ulnar articular surface. The action of biceps anteriorly and triceps posteriorly pull articular surface of Ulna proximally. In an opposing fashion, the humeral shaft is forced distally between the rotated condyles ${ }^{[4]}$.

\section{Methodology}

The study was conducted in Medical College, and there were 14 cases in the study in which 9 were males and 5 females Age of the patients ranged between 25 years and 75 years with an mean age of 48.2 years.

Among the 14 cases, 8 were caused by fall $(57 \%)$ and six were caused by Road Traffic accidents (43\%)

Factures were classified using Riseborough and Radin classification.

Inclusion Criteria: All cases of closed intraarticular fractures of distal humerus in adults

Exclusion Criteria: Open fractures, pathological fracture, Poly trauma.

\section{Technique}

- All cases were done under general anaesthesia.

- Pre-operative antibiotics were given.

- Prone position with elbow flexed over arm board or lateral decubitus position with pillow under arm.

- Tourniquet applied

- Majority of cases were done by Campbells posterior approach.

- Ulnar nerve identified and retracted gently with tape.

- Tongue of ticeps apponeurosis raised.

- Triceps split in midline and tissues retracted sub periosteally.

- Joint surface reconstruction done first.

- Preliminary fixation of joint fragments by $\mathrm{K}$ wire followed by permanent fixation with cancellous or cortical lag crews.

- Reduction and fixation of reassembled condyles to metaphysis with plates or lag screws, ideally by hand contoured $3.5 \mathrm{~mm}$ reconstruction plate or DCP applied on posterior aspect of lateral pillar and one third tubular plate applied at $90^{\circ}$ on medical humeral pillar.

- The tongue defect of triceps aponeurosis repaired.

- Wound closed in layers.
- $\quad$ Above elbow slab applied.

\section{Results}

Among the patients who were above the mean age of 48 years, 3 had acceptable results (average score 88) and 4 had non acceptable results (average score 61.4). All case below the mean age of 48 years had acceptable results (average score -84.28$)$. ' $\mathrm{T}$ ' test was conducted and the results were found to be not statistically significant $(\mathrm{P}>.05)$.

Table 1: Comparison of mean MEPI score based on age

\begin{tabular}{|c|c|c|c|c|c|}
\hline & Age & Mean & $\mathbf{\pm S D}$ & T value & P value \\
\hline \multirow{2}{*}{$\begin{array}{c}\text { MEPI Score } \\
\text { Onset }\end{array}$} & $<48 \mathrm{yrs}$ & 51.25 & 5.82 & \multirow{2}{*}{1.598} & $>0.05$ \\
\cline { 2 - 4 } & $>48 \mathrm{yrs}$ & 44.17 & 9.68 & & \\
\hline $\begin{array}{c}\text { MEPI score } \\
\text { Final follow up }\end{array}$ & $<48 \mathrm{yrs}$ & 76.88 & 12.19 & \multirow{2}{*}{0.553} & $>0.05$ \\
\cline { 2 - 4 } & $>48 \mathrm{yrs}$ & 70.83 & 10.15 & & \\
\hline
\end{tabular}

Fractures were classified using Riseborough and Radin classification. All type II fractures had good results (average score 85). Among type III fractures 6 acceptable results (average score 85.8) and 2 had non-acceptable results (average score 60). All type IV fractures had non-acceptable outcome average score (62.5). ANNOVA test was done and found to be statistically significant $(\mathrm{P}$ value $<.05)$

Table 2: Comparison of mean MEPI score based on type of fracture

\begin{tabular}{|c|c|c|c|c|c|}
\hline & $\begin{array}{l}\text { Riseborough } \\
\text { \& Radin }\end{array}$ & Mean & \pm SD & $\begin{array}{c}\mathbf{F} \\
\text { value }\end{array}$ & $\begin{array}{c}P \\
\text { value }\end{array}$ \\
\hline \multirow{3}{*}{$\begin{array}{l}\text { MEPI Score } \\
\text { Onset }\end{array}$} & II & 51.25 & 4.79 & \multirow{3}{*}{2.169} & \multirow{3}{*}{$>0.05$} \\
\hline & III & 49.38 & $9.43^{\prime}$ & & \\
\hline & IV & 37.50 & 3.54 & & \\
\hline \multirow{3}{*}{$\begin{array}{l}\text { MEPI score } \\
\text { Final follow } \\
\text { up }\end{array}$} & II & 70.00 & 8.10 & \multirow{3}{*}{6.685} & \multirow{3}{*}{$<0.05$} \\
\hline & III & 79.38 & 5.45 & & \\
\hline & IV & 62.50 & 7.61 & & \\
\hline
\end{tabular}

Among the 8 patients operated before meantime of 6 day, 7 patients $(88 \%$ ) had acceptable outcome (average score $86.4 \%$ ) and one had unacceptable outcome (score 70\%). Among the 6 patients operated after 6 days, 3 had acceptable outcome (average score $83.33 \%$ ) and 3 patients had non-acceptable outcome (average score 58.3\%). ' $\mathrm{T}$ ' test was done and the observed differences were not statistically significant ( $\mathrm{P}$ value $>.05)$.

Table 3: Comparison of mean MEPI score based on period between injury and surgery

\begin{tabular}{|c|c|c|c|c|c|}
\hline & $\begin{array}{c}\text { Period } \\
\text { between } \\
\text { Injury and } \\
\text { Surgery }\end{array}$ & Mean & \pm SD & $\begin{array}{c}T \\
\text { value }\end{array}$ & $\begin{array}{c}\mathbf{P} \\
\text { value }\end{array}$ \\
\hline \multirow{2}{*}{$\begin{array}{l}\text { MEPI Score } \\
\text { Onset }\end{array}$} & $<6$ days & 51.25 & 7.44 & \multirow{2}{*}{1.598} & \multirow{2}{*}{$>0.05$} \\
\hline & $>6$ days & 44.17 & 9.17 & & \\
\hline \multirow{2}{*}{$\begin{array}{l}\text { MEPI score } \\
\text { Final follow } \\
\text { up }\end{array}$} & $<6$ days & 76.88 & 11.14 & \multirow{2}{*}{0.553} & \multirow{2}{*}{$>0.05$} \\
\hline & $>6$ days & 70.83 & 10.30 & & \\
\hline
\end{tabular}

\section{Discussion}

DeSault in his original article said "If fingers, placed before or behind, press on the limb in the direction of longitudinal fracture, the condyles will be separated from each other, the one yielding in the outward and the other in an inward direction leaving a fissure or opening between them, the part at the same time expands in breath.

When we take hold of condyles, in each hand and endeavour to make them move in an opposite direction, they can be 
brought alternatively, forward or backward, and if their surfaces touch, a manifest crepitation is hear"

Distinguishing $\mathrm{T}$ or $\mathrm{Y}$ fracture from others is by determining separation from each other and the humeral shaft, with proximal migration of ulna and arm appears shortened, elbow is widened by condylar separation.

There is independent mobility of condyles and they spring back into displacement when pressure is released. Both the pressure and release is extremely painful to patient. The relationship of epicondyles with tip of olecranon is disrupted in fractures with extensive displacement and there is gross instability in all directions ${ }^{[5]}$.

It is essential to take two views (anteroposterior \& lateral) and computerized tomography helps to identify fracture pattern. In fractures gross displacement, diagnosis is easy but due to comminution, origin of many small fragments are difficult to identify. In case of un displaced and minimally displaced, presence of a vertical condylar fracture should be distinguished from a supracondylar fracture.

Due to diverse nature of this fracture and rarity, each case must be individualized. In young adults, near anatomical reduction is necessary to achieve good results. In old individuals, with excessive comminution with osteoporosis, fixation is poor, early restoration of joint movement by nonoperative means leading to restoration of articular congruity gives better results. Therefore, any method that requires prolonged immobilisation leads to fibrosis or ankylosis of joint.

Final X-ray appearance doesn't coincide with the functional results. (Excellent function may be present with distorted $\mathrm{X}$ ray appearance and vice versa).

Initially there were various methods of closed treatment used. The elbow is kept in maximum flexion allowable at the time of fracture because extension is easier to obtain (gravity assisted). Secondly, if ankylosis or restriction of motion of elbow develops in the upper extremity, it is in a better functional position ${ }^{[6]}$.

Recently due to refinement of surgical approach, better fixation devices and reconstruction procedures, anatomical reconstitution of distal humerus is possible and hence the results are better. Therefore, the main flow chart of rigid internal fixation, early mobilisation and rehabilitation has come into practice ${ }^{[7]}$.

East Wood in England in 1930's has claimed 'Hugh Owen Thomas' as the originator of this technique. It is immobilizing the arm in cuff and collar in as much flexion as possible initially, because extension will improve and not flexion. The elbow is left hanging free, as effect of gravity on the dependant elbow fracture fragments align into a more natural alignment ${ }^{[8]}$.

Some attempt at initial reduction is made but permanent success is questionable. Hand \& finger movements are started immediately. Pendulum shoulder exercises are started from 710 day and once pain \& swelling reduces active extension is started. Usually fracture unties in six weeks \& sling is discarded. It has been shown that with intensive physiotherapy range of motion increases in 3 to 4 months. In "Brown \& Morgan series", the average range of motion was $70^{\circ}$.

One author modified his method by applying a large wooden carpenters clamp to condyles \& suspended it from the neck. The clamp was tightened as the swelling decreased. It has its inherent dangers \& due to patients' non-acceptance it was discarded. 'Watson Jones' said residual loss of extension was due to extensive anterior tilt of condyles ${ }^{[9]}$.
Evans achieved satisfactory range of motion and no significant weakness or instability resulted by these methods. But 'Bickell \& Perry' said that it results in an unstable elbow. Hence, this technique is well suited for the elderly and patient motivation and co-operation achieves good results ${ }^{[10]}$.

\section{Conclusion}

- Intra articular fractures of distal humerus in adults are uncommon and are difficult fractures to treat.

- Functional outcome of intra articular fractures in adults are good alter open reduction and internal fixation.

- Age of the patients did not affect the functional outcome after open reduction and internal fixation.

- Simple articular fractures have better functional outcome than comminuted intraarticular fractures.

- Period between injury and surgery had no effect on functional outcome.

\section{References}

1. Jupiter LB, Morrey BF. Fractures of the Distal Humerus. In Morrey, B.F., (ed.): The Elbow and its Disorders, Philadelphia, W.B. Saunder, 1993.

2. Keon-Cohen BT. Fractures at the Elbow. J Bone Joint surg., 1966; 48A:1623-1639,

3. Reich RS. Treatment of Intercondylar Fractures of the Elbow by Means of Traction. J. Bone Joint Surg., 1936; 18:997-1004.

4. Brown RR, Morgan RG. Intercondylar T-shaped Fractures of the Humerus. J. Bone Joint surg. 1971; 53B:425-428,

5. Tynin AH. Intercondylar T-Fractures of the Elbow. J. Bone Joint Surg., 1941; 23:709-711.

6. Miller OL. Blind nailing of the T-Fractures of the Lower End of Humerus Which Involves the. J. Bone Joint Surg., 1939; 21:933-938,

7. Cassebaum WH. Open reduction of $\mathrm{T}$ and $\mathrm{Y}$ fractures of the lower end of the humerus. J. Trauma 1969, 915-918,

8. Kelly RP, Graffin TW. Open reduction of T-Condylar fractures of the humrus. J trauma. 1969; 9:901-914,

9. Aitken GK, Rorabeck CH. Distal Humeral fractures in the adult. Clin. Orthop. 1986; 207:191-198.

10. Helfet DL. Bicondylar Intraarticular Fractures of the Distal Humerus in adults: Their assessment, classification, and operative management, Adv. Orthop. $1985 ; 8: 223-228$. 